\title{
Factors that Influence Experiential Value of Timeshare Owners toward Timeshare Purchasing in Malaysia
}

\author{
${ }^{1}$ Airin NizaZa'ba*, 2 Dileep Kumar M. \\ 10thman Yeop Abdullah Graduate School of Business, Universiti Utara Malaysia, Malaysia \\ ${ }^{2}$ College of Business, Universiti Utara Malaysia, Sintok Kedah, Malaysia \\ *airin.niza@gmail.com
}

\begin{abstract}
This study was conducted to investigate factors that influencing experiential value of timeshareowners in purchasing timeshare in Malaysia. The research framework was constructed based on the extensive literature review to establish the hypothesis. The researcher used questionnaire and the respondents is among the timeshare owners from Malaysia. Quantitative methods were applied in the research for validity. The analysis of the findings of this research reveals that whether involvement ofinfrastructure, security, risk, cost and price would havebring significant experiential value to the timeshare owners.
\end{abstract}

\section{Keywords: Timeshare owner, experiential value, infrastructure, security, risk, cost and price}

\section{Introduction}

Timeshare concept was initiated in 1960s by Alexander Nette in the French Alps. The idea is to purchase the apartment jointly and to share using it based on weekly basis. This model initiated the foundation of the timeshare industry (Madrid, 1996). The same timeshare concept was later entered to America and was adoptedin Florida (Woods, 2001). In the mid-1980s, timeshare was later introduced to Malaysia. Timesharing is a concept which provides for the maximization of the use of a capital asset, by sharing its ownership amongst a number of people, which each of them owning just the time they will use and sharing the costs of ownership in proportion to the amount of time which they own. The rationale of purchasing timesharing is to provide the opportunity buying a holiday home without having burden of the responsibilities of the ownership and maintenance. In Malaysia, the tourism industry has extended greatly in line with the growth of the economy and changing lifestyles of the people. Timesharing is a natural extension of the tourism industry and a number of companies, including subsidiaries of listed companies and hotel chains have ventured into this industry to tap the growth of this industry. However, during recession in 2008, the statistics of the timeshare industry was affected and shrink causing the timeshare industry facing severe challenges for future development. Finding shows that owners are more interested in selling their timeshare than in buying additional new ones (ADRA International Foundation, 2010b; ADRA International Foundation, 2011b). Apart from the internal challenges, timeshare industry also faces competitions on other services competitors in the hospitality industry such as cruise travel, tourism packages and luxury hotels. Therefore, it is crucial to evaluate what factors that can influence the experiential value of timeshare owners' to purchase timeshare.

\section{Literature Review}

Infrastructure: Infrastructure is referred to the resort unit which is the accommodation that provided to the consumers during their stay. The unit can have a number of physical factors that separate it from other units such as view, square footage, floor plan, and number of bedrooms provided. Resort units usually contain many of the items associated with hotel rooms with the addition of some of the same comforts as an individual's home (washer, dryer, kitchen equipment) (ARDA, 2005). Some resorts will have additional luxuries that go beyond the traditional comforts of home, such as Roman-style whirlpools, lush arrangements of silk greenery, and spacious vanity areas (ARDA, 2005). The furniture, fixtures and equipment associated with the resort unit are what make it appealing to a consumer and are shown to the prospective buyer during a sales tour by a sales person (ARDA, 2005). According to research by Wilkins et al. (2007), some of the more important items regarding unit experience are its cleanliness, the comfort, and the quality of the items contained within the rooms. 
Timeshare Purchasing - Cost and Price: Woods (2001), discussed the major challenges facing the timeshare industryand generated a laundry list that includes ethics, capitalization costs, regulations, marketing costs, sales practices and timeshare resale issues. Timeshare costs are quite expensive because consumers are required to purchase their stays in advanced together with the maintenance fees. Apart from that, there will also be additional fees for certain exchanged resorts. Hovey (2002) highlighted three aspects which are the cost of sales, maintenance costs and exit costs that will contribute to the costs of ownership of timeshare that are considered as factors that could beaddressed to make timeshare ownership more feasible. If the industry were able to take up the challenge of reducing these there costs in, it is likely that investment in timeshare would be more viable and attract a wider market.

Security: Every hospitality customer is concerned about physical safety, financial security, and confidentiality. The service provider should make sure that the customer is made comfortable during the stay (Kumar, 2010). Timeshare resorts are very similar in operations to a traditional hotel or resort, giving them the same types of factors to focus on in the design and implementation of services. They would have the same concerns associated with cleanliness and quality along with the additional concerns of landscaping and safety and security (ARDA, 2005). Landscaping can enhance the theme of the resorts and add to the curb appeal from a sales perspective. The safety and security measures of a resort are represented by the presence of safety/security officers, signs throughout the property, fencing around the perimeter, and key-lock entry into guest areas. These enhance the product by giving a sense of exclusivity to the resort while further enhancing the tangible timeshare resort experience.

Risk: There are various risks that related to owing a time-share interval (Hovey, 2002 and Larson \& Larson, 2009). Consumers should carefully review the risks of owning a timeshare. Risks from owning a timeshare is reflected in the discount rate based on the study by Stephen (2012).According to Stephen (2012), there are nine (9) risks that timeshare owners need to consider which are;

- if the resorts end up being unsold

- timeshare owners may be need to pay for the extra charges due to unexpected events such as losses that are not fully covered by insurance

- Agency problem which is quite possible especially if the resort's managers are not among the ownership stake in the timeshare resort, this will cause underperform and poor maintenance.

- economic recession - other owner would increase management costs

- the exchange program for alternate location could be default resulting additional fees need to paid for the exchange program

- increase owner's level of financial risk by adding commitment or fixed costs to the household expenses

- the resorts location and its resale value

- political risk if the resort is located in another country

- Exchange rate risk which can impact the cash flows where appreciating currency will have higher management fees dominated by the foreign currency and vice versa for the depreciating currency.

Experiential Value: According to Sparks, Butcher and Pan (2007) regarding the perceived value of a timeshare purchase, customer value was normally considered to be an antecedent of customer satisfaction. From their study, it shows that ownership and pride, new experience, flexibility, luxury and reward were some of the components of owning a timeshare that provided value forthem, thus enhancing their satisfaction with the product. This study delivered a new focus that organizations could use when marketing to approaching timeshare owners, as well as a method to promote the value and increase the overall satisfaction of the owners. Sparks et al. (2007) measured timeshare owners to discover where value is derived from. They found out that as owners are aware about additional options for using their timeshare units such as renting out, exchange for different resort locations or convert it into points that could be used to purchase services like vacations at other hotels or airline tickets, the timeshare value increased.

Problem Formulation: This study is mainly to measures the gap between factors that timeshare owners consider during purchasing and value gained by them. The investigation part will be more on answering the following research questions: (1) what are the factors that associates with the purchasing timeshare program in Malaysia? (2) The researcher is interested to understand why owners would buy the products even though it is costly. 
Objectives: The objectives of this research are to measure the pre-factors affecting customer experiential value. It is to examine the associations between factors elements and experiential value. An overall concept and framework were proposed to examine these relationships.

Hypothesis: The following five hypotheses are constructed to identify the factors affecting experiential value of timeshare owners. They are:
$\mathrm{H}_{0}=$ Null hypothesis
$\mathrm{H}_{1}=$ Alternative hypothesis

Hypothesis No.1:

$\mathrm{H} 1_{0}$ : There is no significant relationship between infrastructures with experiential value

$\mathrm{H} 1_{1}$ : Infrastructure is positively related to experiential value

Timeshare owners often look forward for a quality and comfortable vacation. Therefore the infrastructure of the resort or hotel is important. According to a study by Wilkins et al. (2007) as mentioned in the literature review above, some of the important items regarding unit experience are mainly on the cleanliness, the comfort, and the quality of the items contained within the rooms or units of the hotel.

Hypothesis No.2:

$\mathrm{H} 2_{0}$ : There is no significant relationship between securities with experiential value

$\mathrm{H} 2_{1}$ : Security is positively related to experiential value

According to Kumar (2010) every hospitality customer is concerned about physical safety, financial security, and confidentiality. The hotel management should ensure that the customer is comfortable during the stay.

Hypothesis No.3:

$\mathrm{H} 3_{0}$ : There is no significant relationship between risks with experiential value

$\mathrm{H} 3_{1}$ : Risk is positively related to experiential value

The risks associated with any buyingmust be considered, mainly when comparinginvestment opportunities. Ideally an inventor should be compensated for the risk borne. There isalso the question related with valuing timeshare as to whether the risk-free discount rate isappropriate.Accordingly, from the timeshare perspective, it is the risk associated with the capacity of a consumer to sell a timeshare investment quickly and at a fair price. If an owner is required to reduce the price below market value or fair value, or takes extensive time to divest the investment, then it is considered illiquid (Hovey, 2002).

Hypothesis No.4:

$\mathrm{H} 4_{0}$ : There is no significant relationshipbetween cost and price with experiential value

$\mathrm{H}_{4}{ }_{1}$ : Cost and price is positively related to experiential value

There is ample literature that emphasizes the relationship between cost and price with experiential value.

Conceptual and Operational Detentions: The purpose of this study is to determine the four factors that influence experiential value of timeshare owners during purchasingof timeshare. All 25 items are divided intofive dimensions which are infrastructure, security, risk, cost and price, and experiential value.The research framework is shown in Figure 1.

Figure 1: Research framework

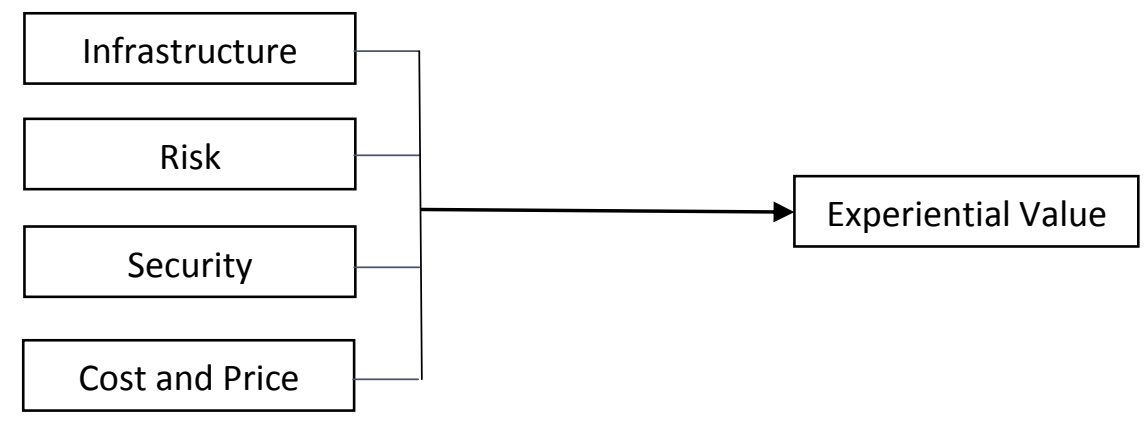

\section{Methodology}

A questionnaire was adopted and modified to fit this study on timeshare industry. It was distributed using a convenience sampling technique to the timeshare owners in Malaysia to determine their perceptions of purchasing the timeshare. In this research, the relationship between factors and consumers' experiential value is investigated. The consumers' perceptions of different aspects attributes 
are evaluated. The data used in this research is primary data by close-end questionnaire, regarding owners' perception and aspects, with 25 different elements and items. The first section of the questionnaire is aimed at gathering information on the respondents' demographic. In the second section of the questionnaire, therespondents were asked to rate their perceptions on what factors that influencing them in converting the timeshare purchasing into experiential value.

Table 1: Profile of survey respondents

\begin{tabular}{llll}
\hline Characteristics & Descriptions & Statistics & (\%) \\
\hline $1 . \quad$ Gender & Male & 61 & $(44.5)$ \\
& Female & 76 & $(55.5)$ \\
$2 . \quad$ Age & $17-24$ & 36 & $(26.3)$ \\
$25-34$ & 76 & $(55.5)$ & \\
$35-44$ & 15 & $(10.9)$ & \\
45 and above & 9 & $(6.6)$ & \\
\hline
\end{tabular}

A total of 137 questionnaires were received and analyzed. Table 1 shows the profile of survey respondents. The largest group of respondents is female with 76 respondents $(55.5 \%)$ and male are 61 respondents (44.5\%). As for age group, the highest group of respondents are age 25 to 34 with the percentage of $55.5 \%$, and the least group are from age 45 and above with the percentage of $6.6 \%$.

\section{Result and Discussion}

The research analyze on the data reliability using Cronbach's Alpha coefficient. A reliability coefficient of 0.6 and above is considered acceptable in most social science research. To test the reliability, the Cronbach's alpha was estimated for each of the five factors in this research. Table 2 shows the reliability results of the five factors.

\section{Table 2: Reliability statistics}

\begin{tabular}{lll}
\hline Factor & Cronbach's Alpha & N of items \\
\hline 1. Infrastructure & 0.819 & 3 \\
2. Security & 0.883 & 3 \\
3. Risk & 0.862 & 3 \\
4. Cost and Price & 0.784 & 3 \\
5. Experiential Value & 0.923 & 5 \\
\hline
\end{tabular}

Table 3: Factor analysis (Rotated Component Matrix ${ }^{a}$ )

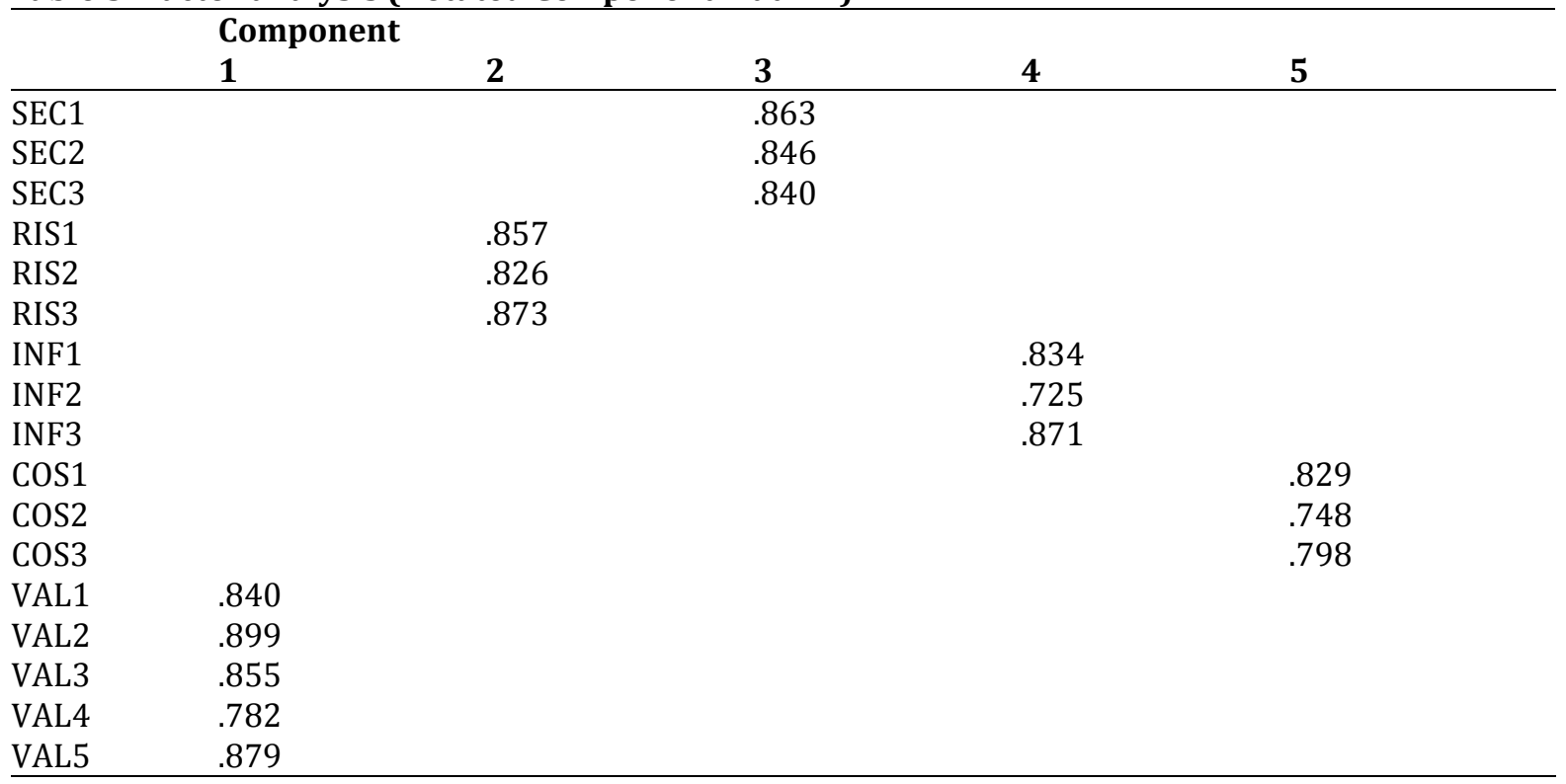

Extraction Method: Principal Component Analysis.

Rotation Method: Varimax with Kaiser Normalization.

a. Rotation converged in 6 iterations. 
Based on Table 2, Cronbach's Alpha results show that the alpha coefficients ranged from 0.784 to 0.923 for the five factors. The results are considered reliable, since 0.60 is the minimum value for accepting the reliability test. Factor analysis is usually run for data reduction and is implemented by reviewing the pattern of correlations between the observed measures which are highly correlated, either positively or negatively. They are expected to influence by the same factors, while those that are relatively uncorrelated are expected to be influenced by different factors (DeCoster, 1998). Table 3 shows the factor loadings for each item in relation to the various factors. Based on Table 3, these values show the weight and correlation of each item has a factor or component. It can be realized that items from same dimension are regrouped under the same factor. This factor analysis proves that the questionnaire adopted is a good measure of factors in the timeshare experiential value because we expect to see similar items categorized under the same factor showing that they measure the same thing.

Table 4: KMO and Bartlett's Test

\begin{tabular}{lll}
\hline \multicolumn{1}{l}{ Kaiser-Meyer-Olkin Measure of Sampling Adequacy. } & 0.797 \\
\multirow{3}{*}{ Bartlett's Test of Sphericity } & Approx. Chi-Square & 1361.709 \\
& df & 136 \\
& Sig. & 0.000 \\
\hline
\end{tabular}

Table 4 show the KMO's test ranged between 0 and 1 . According to Field (2005), a value of 0 indicates that the sum of partial correlations is large relative to the sum of correlations meaning factor analysis is expecting to be irrelevant while a value close to 1 , shows that patterns of correlations are fairly compact and factor analysis yield distinct and reliable factors. For this data, the value is 0.797 , which shows that the factor analysis is relevant for this research. The correlations compute the linear of the relationship between the two variables and also showing the direction of the relationship. The correlation coefficient $r$, measures the strength of the linear relationship. $R$ value is between +1 and -1 . If $R$ near to +1 or -1 indicates a strong linear relation. If $r$ close to 0 represents the linear association is very weak. Table 5 shows the correlations of each factor.

Table 5: Correlations

\begin{tabular}{lcccc}
\hline Factor & SEC & RIS & INF & COS \\
\hline Pearson Correlation & 0.484 & -0.151 & -0.161 & -0.148 \\
Sig. (2-tailed) & 0.000 & 0.089 & 0.068 & 0.094 \\
$\mathrm{~N}$ & 137 & 137 & 137 & 137 \\
\hline
\end{tabular}

Based on Table 5, the results shows there is a significant and positive relation between security (SEC) and experiential value, $r=0.484$ at 0.05 significant level. However, risk (RIS), infrastructure (INF) and cost and price (COS) present a negative relation, $r=-0.151,-0.161$ and -0.148 , respectively and has a nonsignificant correlation with experiential value at the 0.05 significant level. Based on the correlations results, hypothesis $\mathrm{H} 21$ will be accepted. It means security is positively correlates with experiential value. Higher security leads to more experiential value to the timeshare owners. On the other hand, hypothesis $\mathrm{H} 10$ will be accepted and $\mathrm{H} 11$ will be rejected which means there is no significant relationship (p-value is more than 0.05 ) between infrastructure and experiential value. This may due to some of the timeshare owners have no preference on luxury resort with fully equipped facilities such as having kitchen in the unit, swimming pool and gymnasium. They are more emphasizing on the location or different country and places of the availability of the timeshare resorts such as in Europe, U.S. Australia and etc. Hypothesis $\mathrm{H} 30$ will be accepted and $\mathrm{H} 31$ is rejected, because the results shows there is no significance relationship ( $p$-value is more than 0.05 ) and risk is negatively correlated with experiential value. This shows that higher the risk will give lower experiential value to timeshare owners.

Table 6: R2Model Summary

\begin{tabular}{ccclcc}
\hline Model & $\mathrm{R}$ & & R Square & Adjusted R Square & Std. Error of the Estimate \\
\hline 1 & 0.562 & 0.316 & 0.293 & 3.29625 & \\
\hline
\end{tabular}

Lastly, $\mathrm{H} 40$ will be accepted and $\mathrm{H} 41$ will be rejected. It shows there is no significant relationship (p-value is more than 0.05 ) between cost and price with experiential value. Cost and price is negatively correlated with experiential value. This shows that higher the cost and price will leads to lower experiential value to timeshare owners. Based on Table 6, R is the correlation coefficient measuring the strength of the linear 
relationship $\mathrm{R}=0.562$ shows moderate relationship. $\mathrm{R}$ square is the coefficient of determination, it tells us that this model can predict $31.6 \%$ of the variables correctly.

Research Findings: Nowadays, the Malaysia Government has set a high priority on the tourism industry. Sustainable growth of tourism industry depends on a good plan for related services and facilities. The importance of experiential value makes it necessary to influence the purchasing of timeshare. Measurement of influencing factors toward experiential value of timeshare purchasing help the timeshare organizations to understand the motivations and behaviors of timeshare owners and use it to increase industry performance. From the four hypotheses, security influencing factor shows positive relationship with experiential value. This shows that every timeshare owners are concern about their physical safety, financial safety and confidentiality during the stay. The higher the security, the more comfortable feelings felt by the timeshare owners during the stay. According to Shahrivar (2012), there are security and safety problems in the tourism industry. Therefore in order to motivate timeshare purchasing, timeshare organizations needs to enhance the security system of their resort to give a sense of exclusiveness experiences to the timeshare owners. The safety and security of a resort are like the presence of safety/security officers, camera closed-circuit television, signs throughout the property, fencing around the perimeter, and key-lock entry into guest areas. Other results like infrastructure, cost and price, and risk do not show a significant experiential value influence toward timeshare purchasing. It could be no association at all or the relationship in non-linear. In addition, this may due to there are other factors that are influencing the experiential value toward timeshare purchasing and have not identified out.

\section{Conclusion}

In conclusion, the timeshare players can benefit from this study after knowing the most important influence factor that lead to timeshare purchasing. As this can help the timeshare company in Malaysia to provide a better service quality to their timeshare owners. For example, better security quality by Palace Vacation Clubas a timeshare resorts. Future research can be conducted using more influencing factors and sample size.

Recommendations: There is a limitation in this study is the survey done was distributed by using social media to timeshare owners in Malaysia, and was collected using e-form. There is a probability that the questionnaire is not evenly distributed among the age group due to technological exposure constraints. The researcher recommended that for future research should be involved the participation of the timeshare organizations for wider data collection.

\section{References}

ADRA International Foundation [AIF]. (2010b). State of the Vacation Timeshare Industry: United States Study. American Resort Development Association.

ADRA International Foundation [AIF]. (2011b). State of the Vacation Timeshare Industry: United States Study. American Resort Development Association.

ARDA. (2005). The Timeshare industry resource manual. Washington, DC: American Resort Development Association.

DeCoster, J. (1998). Overview of Factor Analysis.Retrieved Nov, 2014 from http://www.stathelp.com/notes.html

Kumar, P. (2010). Marketing of hospitality and tourism services. Tata McGraw Hill Education Private Limited. Pg 39.

Hovey, M. (2002). Is timeshare ownership an investment product? Journal of Financial Services Marketing, $7(2)$.

Madrid. (1996). The new force in tourism. World Tourism Organization. Madrid, Spain.

Shahrivar, R. B. (2012). Factors that influence tourist satisfaction. Journal of Travel and Tourism Research, JTTR-2012 Special Issue

Sparks, B., Butcher, K. \& Pan, G. (2007). Understanding Customer-Derived Value in the Timeshare Industry. Cornell Hotel \& Restaurant Administration Quarterly, 48(1), 9-9.

Stephen, J. L. (2012). Estimating the Breakeven Value of a Time Share Interval. Journal of Financial and Economic Practice, 12(3), 70-76.

Wilkins, H., Merrilees, B. \& Herington, C. (2007). Towards an understanding of total service quality in hotels. International Journal of Hospitality Management, 26(4), 840-853.

Woods, R. H. (2001). Important Issues for a Growing Timeshare Industry. The Cornell Hotel and Restaurant Administration Quarterly, 42(1), 71-81. 